\title{
Modelling adhesive joints with cohesive zone models: effect of the cohesive law shape of the adhesive layer
}

\author{
R.D.S.G. Campilho, M.D. Banea, J.A.B.P. Neto, L.F.M. da Silva
}

\begin{abstract}
Adhesively-bonded joints are extensively used in several fields of engineering. Cohesive Zone Models (CZM) have been used for the strength prediction of adhesive joints, as an add-in to Finite Element (FE) analyses that allows simulation of damage growth, by consideration of energetic principles. A useful feature of CZM is that different shapes can be developed for the cohesive laws, depending on the nature of the material or interface to be simulated, allowing an accurate strength prediction. This work studies the influence of the CZM shape (triangular, exponential or trapezoidal) used to model a thin adhesive layer in single-lap adhesive joints, for an estimation of its influence on the strength prediction under different material conditions. By performing this study, guidelines are provided on the possibility to use a CZM shape that may not be the most suited for a particular adhesive, but that may be more straightforward to use/implement and have less convergence problems (e.g. triangular shaped CZM), thus attaining the solution faster. The overall results showed that joints bonded with ductile adhesives are highly influenced by the CZM shape, and that the trapezoidal shape fits best the experimental data. Moreover, the smaller is the overlap length $\left(L_{0}\right)$, the greater is the influence of the CZM shape. On the other hand, the influence of the CZM shape can be neglected when using brittle adhesives, without compromising too much the accuracy of the strength predictions.
\end{abstract}

Keywords: Epoxy/epoxides, Composites, Finite element stress analysis, Fracture

\section{Introduction}

Adhesively-bonded joints are extensively used in several fields of engineering, such as automotive, aeronautical and space structures, as an easy method to join components, assuring at the same time the design requirements for the structure [1] General capabilities of this joining method involve more uniform stress fields than fastening or riveting, fluid sealing, high fatigue resistance, and possibility to join different materials on account of corrosion prevention and accommodation of different thermal expansion of the adherends $[2,3]$. The techniques for strength prediction of bonded joints also improved. Initially, theoretical methods (mainly closed-form) were proposed for stress distributions in the adhesive for simple geometries such as the single or double-lap joint, and failure estimation was carried out by comparison of the maximum stresses with the material strengths [4]. Some decades later, the FE initiated its incursion in the analysis of adhesively-bonded joints (e.g. the work of Wooley and Carver [5]), by consideration of stress/strain or fracture mechanics criteria for failure prediction [6]. Even though these analyses were promising, they had few limitations: stress/ strain predictions depend on the mesh size at the critical regions, while fracture criteria such as the Virtual Crack Closure Technique (VCCT) are restricted to Linear Elastic Fracture Mechanics (LEFM) and need an initial crack. CZM have been used in the last decade for the strength prediction of adhesive joints, as an add-in to $\mathrm{FE}$ analyses that allows simulation of damage growth within bulk regions of continuous materials or interfaces between different materials $[7,8]$. Compared to conventional $\mathrm{FE}$, a much more accurate prediction is achieved, since different shapes can be developed for the cohesive laws, depending on the nature of the material or interface to be simulated. The triangular and trapezoidal CZM shapes are most commonly used for strength prediction of typical structural materials. For the application of this technique, traction-separation laws with a pre-defined shapeare established at the failure paths, and the values of energy release rate in tension and shear $\left(G_{\mathrm{n}}\right.$ and $G_{\mathrm{s}}$, respectively) along the fracture paths and respective critical values or toughness $\left(G_{\mathrm{n}}^{\mathrm{c}}\right.$ and 
$\left.G_{\text {s. }}^{c}\right)$ are required. The cohesive strengths in tension and shear ( $t_{\mathrm{n}}$ and $t_{\mathrm{s}}$, respectively) are equally needed and they relate to damage initiation, i.e. end of the elastic behaviour and beginning of damage. Different techniques are nowadays available for the definition of the cohesive parameters $\left(G_{\mathrm{n}}^{\mathrm{c}}, G_{\mathrm{s}}, t_{\mathrm{n}}\right.$ and $\left.t_{\mathrm{s}}\right)$, such as the property identification technique, the direct method and the inverse method. These methods usually rely on the DoubleCantilever Beam (DCB), End-Notched Flexure (ENF) or single-lap specimens, generally with good results [9-13]. The property identification technique consists on the separated calculation of each one of the cohesive law parameters by suitable tests, while in the inverse method the CZM parameters are estimated by iterative fitting the $\mathrm{FE}$ prediction with experimentally measured data (typically the load-displacement, $P-\mathrm{d}$, curve) up to an accurate representation. Both of these approaches begin with the assumption of a CZM shape to simulate a specific material, which approximately replicates it in terms of post-elastic behaviour [14]. On the other hand, the direct method gives the precise shape of the CZM laws of a specific material or interface, since these are estimated from the experimental data of fracture tests such as the DCB or ENF [15]. This is done by differentiation of $G_{\mathrm{n}}$ (tension) or $G_{\mathrm{s}}$ (shear) with respect to the relative opening of the crack $\left(d_{n}\right.$ for tension or $d_{s}$ for shear). Nonetheless, it is usual to convert the obtained shape in an approximated parameterized shape for introduction in the FE software. Carlberger and Stigh [16] estimated the CZM law shapes of a thin adhesive layer in tension and shear with DCB and ENF tests, respectively, for an adhesive thickness, $t_{\mathrm{A}}$, between 0.1 and $1.6 \mathrm{~mm}$. The cohesive laws were found by a direct method based on the differentiation of the $G_{\mathrm{n}} / G_{\mathrm{s}}$ vs. $\mathrm{d}_{\mathrm{n}} / \mathrm{d}_{\mathrm{s}}$ data. The CZM shapes and respective parameters significantly varied with $t_{\mathrm{A}}$, ranging from a rough triangular shape for the smaller values of $t_{\mathrm{A}}$ to a trapezoidal shape for bigger values of $t_{\mathrm{A}}$.

It is thus recommend adjusting the shape of the CZM laws to conform to the behaviour of the thin material strip or interface they are simulating. Developed CZM include triangular [17], linear-parabolic [18], polynomial [19], exponential [20] and trapezoidal laws [21]. Thus, CZM can also be adapted to simulate ductile adhesive layers, whose behaviour can be approximated with trapezoidal laws [14]. Although it is always advised the use of the most suitable CZM shape and to perform accurate parameter estimations, few works showed acceptable predictions for small variations to the optimal CZM parameters and shapes $[11,22]$. On the other hand, the effect of the CZM law shape on the strength predictions significantly varies depending on the structure geometry and post-elastic behaviour of the materials. These issues became evident in the experimental and FE study of Pinto et al. [23], whose objective was the strength comparison of single-lap joints with similar and dissimilar adherends and values of adherend thickness, $t_{\mathrm{p}}$, bonded with the adhesive $3 \mathrm{M}$ DP$8005^{\mathrm{S}}$. The accurate shape of the CZM law was considered fundamental for the strength prediction and $P-\mathrm{d}$ response of the structure when using stiff adherends. Under these conditions, peel stresses are minimal and, due to the large longitudinal stiffness, shear stresses distribute more evenly along the bond length. Thus, the $P-\mathrm{d}$ curve is very similar in shape to the chosen shear CZM law. On the other hand, compliant adherends led to large shear and peel stress gradients. Since this implies different damage states along the adhesive layer, using an inaccurate CZM law gives adhesive stresses that are over predicted at some elements and under predicted at others. Thus, by using compliant adherends the overall behaviour gave smaller errors. Ridha et al.

[24] considered scarf repairs on composite panels bonded with the high elongation epoxy adhesive $\mathrm{FM}^{\mathbf{S}}$ 300M (Cytec). CZM laws with linear, exponential and trapezoidal softening were compared, and linear degradation resulted in under predictions of the repairs strength of nearly $20 \%$, on account of excessive plastic degradation at the bond edges that was not observed in the real joints. Regarding the application of CZM for strength prediction of adhesive bonds, trapezoidal laws are recommended for ductile adhesives [8,25], and this is particularly critical when considering stiff adherends, due to the practically absence of differential deformation effects in these components along the overlap $[23,26]$. In contrast, triangular CZM are efficient for brittle materials that do not plasticize by a significant amount after yielding [27], and also for the intralaminar fracture of composite adherends in bonded structures, due to their intrinsic brittleness [28]. For adhesives that exhibit a relatively brittle behaviour in tension while showing large plastic flow in shear, the proper selection of the CZM parameters and also the minimisation of the constant stress (plastic flow) region in the tensile law result on a good representation of the adhesive behaviour. The material/interfacial behaviour that the CZM law is simulating should always be the leading decision factor to select the most appropriate shape. Despite this fact, other issues should be taken into account [7]. In fact, the CZM law shape also influences the iterative solving procedure and the time required to attain the solution of a given engineering problem: larger convergence difficulties in the iterative solving procedure usually take place for trapezoidal rather than triangular CZM laws, due to the more abrupt change of stiffness in the cohesive elements during stress softening. Actually, for a fixed value of the material properties $G_{\mathrm{n}}^{\mathrm{c}}$ and $G_{s}^{\mathrm{c}}$, the larger the constant stress length of the trapezoidal law, the bigger is the descending slope. Additionally, exponential and trapezoidal CZM are more difficult to formulate and implement in FE software.

This work studies the influence of the CZM shape (triangular, exponential or trapezoidal) used to model a thin adhesive layer in single-lap adhesive joints, for an estimation of its influence on the strength prediction under different material conditions. The FE software Abaqus ${ }^{\mathbf{s}}$ (Providence, RI, USA) and its embedded CZM formulation were used in this work. As a result of this study, some conclusions were established to assess the importance of using a CZM shape for a given adhesive that accurately predicts the joint strength, under different material conditions (i.e., considering a brittle and a ductile adhesive)

\section{Experimental work}

\subsection{Materials characterisation}

Unidirectional carbon-epoxy pre-preg (SEAL ${ }^{S}$ Texipreg HS $160 \mathrm{RM}$; Legnano, Italy) with $0.15 \mathrm{~mm}$ thickness was considered for the composite adherends of the single-lap joints, with the $[0]_{16}$ lay-up. Table 1 presents the elastic properties of a unidirectional lamina, modelled as elastic orthotropic in the $\mathrm{FE}$ analysis [29]. Two epoxy adhesives were considered. The adhesive Araldite $^{\mathbf{s}}$ AV138 is a two-part (resinphardener) brittle and high strength adhesive suited to bond a large variety of materials such as metals or polymers/polymer composites. The adhesive Araldite $\mathbf{S} 2015$ is equally a two-part structural adhesive, showing

Table 1

Elastic orthotropic properties of a unidirectional carbon-epoxy ply aligned in the fibres direction ( $x$-direction; $y$ and $z$ are the transverse and through-thickness directions, respectively) [29].

\begin{tabular}{|c|c|c|}
\hline$E_{x} 1 / 41.09 \mathrm{E} \mathbf{p} 05 \mathrm{MPa}$ & $\mathrm{n}_{x y^{1 / 4} / 0.342}$ & $G_{x y^{1 / 4} / 4315 \mathrm{MPa}}$ \\
\hline$E_{y}^{1 / 488819} \mathrm{MPa}$ & $\mathrm{n}_{x z} z^{1 / 40.342}$ & $G_{x z} 1 / 44315 \mathrm{MPa}$ \\
\hline$E_{2} 1^{1 / 4} 8819 \mathrm{MPa}$ & $\mathrm{n}_{y z} z^{1 / 4} 0.380$ & $G_{y z} 1 / 43200 \mathrm{MPa}$ \\
\hline
\end{tabular}


a smaller ultimate strength than the previous, but allowing large plastic flow prior to failure. This is an important feature for bonded joints as it allows redistribution of stresses at stress concentration regions, which usually takes place because of the sharp edges at the overlap ends and also joint asymmetry/distinct deformation of the adherends along the overlap. The adhesives were previously characterised regarding the elastic moduli in tension and shear ( $E$ and $G$, respectively), the failure strengths in tension and shear (corresponding to $t_{\mathrm{n}}$ and $t_{\mathrm{s}}$ ) and the values of $G_{\mathrm{n}}^{\mathrm{c}}$ and $G_{\mathrm{s}}^{\mathrm{c}}$. For the adhesive characterisation, bulk tests were performed to characterise the adhesives in tension and Thick Adherend Shear Tests (TAST) were chosen for shear characterisation. It should be pointed out that the cohesive strengths of thin adhesive layers and the bulk strengths of adhesives are different quantities [30]. This is because bulk adhesives are homogeneous materials cracking perpendicularly to the maximum principal stress direction, while adhesives as thin layers are highly constrained between stiff adherends and damage growth under these conditions occurs under mixed-mode (tension plus shear) and along the predefined path of the bonding direction. In this work, the cohesive strengths of the adhesives were assumed as equal to their bulk quantities as an approximation. The good correspondence that was observed by the comparisons to the experimental data allowed to assume that a fair approximation was attained and to corroborate the use of these properties.

The bulk specimens were manufactured following the NF T 76-142 French standard, to prevent the creation of voids. Thus, $2 \mathrm{~mm}$ thick plates were fabricated in a sealed mould, followed by precision machining to produce the dogbone shape described in the standard. The TAST characterisation of the adhesive was carried out according to the 11003-2:1999 ISO standard, considering DIN Ck 45 steel adherends. More details about the fabrication and testing procedures can be found in reference [31]. Characterisation of the adhesives regarding the elastic constants, strengths and strains in tension and shear, was previously conducted in the work of da Silva et al. [32] (Araldites AV138) and by the authors in a previous work [33] (Araldites 2015). The values of $G_{\mathrm{n}}$ and $G_{\mathrm{s}}^{\mathrm{c}}$ for the AV138 were determined by the authors in [27] by numerical fitting procedures. The authors also estimated in a previous work the values of $G_{\mathrm{n}}$ and $G_{\mathrm{s}}$ for the 2015 [33], by DCB $\left(G_{\mathrm{n}}\right)$ and ENF tests $\left(G_{\mathrm{s}}\right)$ using different Fracture Mechanics data reduction methods. The relevant mechanical properties of these adhesives, which were used to construct the cohesive laws, are summarised in Table 2 (the initial yield stress was calculated for a plastic strain of $0.2 \%$ ). The large difference between $G_{\mathrm{n}}^{\mathrm{c}}$ and $G_{\mathrm{s}}$ observed in Table 2 is typical of ductile structural adhesives, which show a significantly larger plastic flow in shear than in tension [34].

Table 2

Properties of the adhesives Araldite ${ }^{\text {s }}$ AV138 and 2015 [27,32,33]

\begin{tabular}{lll}
\hline Property & AV138 & 2015 \\
\hline Young's modulus, $E[\mathrm{GPa}]$ & 4.8970 .81 & 1.8570 .21 \\
Poisson's ratio, $\mathrm{n}^{\mathrm{b}}$ & 0.35 & 0.33 \\
Tensileyield strength, $\mathrm{S}_{\mathrm{y}}[\mathrm{MPa}]$ & 36.4972 .47 & 12.6370 .61 \\
Tensile failure strength, $\mathrm{S}_{\mathrm{f}}[\mathrm{MPa}]$ & 39.4573 .18 & 21.6371 .61 \\
Tensile failure strain, $\mathrm{e}_{\mathrm{f}}[\%]$ & 1.2170 .10 & 4.7770 .15 \\
Shear modulus, $G[\mathrm{GPa}]$ & 1.5670 .01 & 0.5670 .21 \\
Shear yield strength, $\mathrm{t}_{\mathrm{y}}[\mathrm{MPa}]$ & 25.170 .33 & 14.671 .3 \\
Shear failure strength, $\mathrm{t}_{\mathrm{f}}[\mathrm{MPa}]$ & 30.270 .40 & 17.971 .8 \\
Shear failure strain, $\mathrm{g}_{\mathrm{f}}[\%]$ & 7.870 .7 & 43.973 .4 \\
Toughness in tension, $G_{\mathrm{h}}^{\mathrm{c}}[\mathrm{N} / \mathrm{mm}]$ & $0.20^{\mathrm{a}}$ & 0.4370 .02 \\
Toughness in shear, $G_{\mathrm{s}}^{\mathrm{c}}[\mathrm{N} / \mathrm{mm}]$ & $0.38^{\mathrm{a}}$ & 4.7070 .34 \\
\end{tabular}

\footnotetext{
${ }^{\text {a }}$ Estimated in reference [27].
}

${ }^{b}$ Manufacturer's data.

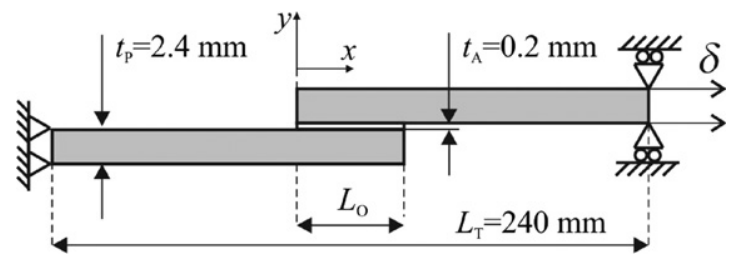

Fig. 1. Geometry and characteristic dimensions of the single-lap joints.

\subsection{Joint fabrication and testing}

The single-lap joint geometry and characteristic dimensions are represented in Fig. 1. The following dimensions were considered $(\mathrm{mm}): L_{\mathrm{O}} 1 / 4$ 10-80, width $b^{1 / 4} 15$, total length between gripping points $L_{\mathrm{T}} 1 / 4240, t_{\mathrm{P}}^{1 / 4} 2.4$ and $t_{\mathrm{A}} 1 / 40.2$. Eight different values of $L_{0}$ were evaluated $(10,20,30,40,50,60,70$ and $80 \mathrm{~mm})$. The joints were fabricated by the following steps: (1) the surfaces to be bonded were roughened by manual abrasion with 220 grit sandpaper and cleaned with acetone, (2) the joints were bonded in an apparatus for the correct alignment, and the desired value of $t_{\mathrm{A}}$ was achieved during assembly with a dummy adherend and a $0.2 \mathrm{~mm}$ calibrated spacer under the upper adherend, jointly with the application of pressure with grips and (3) tabs were glued at the specimen edges for a correct alignment in the testing machine. The reported method for the joints assembly assured the precision of the obtained $t_{\mathrm{A}}$ values, to reduce test data scatter to a minimum. The joints were left to cure at room temperature for 1 week to assure complete curing, and the excess adhesive at the bonding region was then removed by precision milling to provide square-edges at the overlap edges. Tensile testing to the joints was carried out in an Instron $\mathbf{s} 4208$ (Norwood, MA, USA) electro-mechanical testing machine with a $100 \mathrm{kN}$ load cell, at room temperature and under displacement control $(0.5 \mathrm{~mm} / \mathrm{min})$. The testing machine grips displacement was considered to build the $P-\mathrm{d}$ curves. For each value of $L_{\mathrm{O}}$, six specimens were tested, with at least four valid results.

\section{Numerical study}

\subsection{FE simulation}

The FE software Abaqus ${ }^{\mathbf{s}}$ was considered for this study, to evaluate the modelling accuracy of its CZM embedded formulation when stipulating different CZM shapes to model the adhesive layer in single-lap joints. A geometrically non-linear static analysis was performed [14,35], modelling the adherends with the elastic orthotropic properties of Table 1. Fig. 2 depicts an example of FE mesh for the $L_{O}^{1 / 4} 10 \mathrm{~mm}$ joint. The meshes for all $\mathrm{FE}$ models were automatically created by the software considering bias effects, with smaller sized elements near the overlap edges and in the thickness direction near the adhesive. Actually, it is known that the overlap edges are theoretically singularity spots with large stress variations [36]. To provide identical modelling conditions, the FE elements size in all models was made equal at the overlap edges (approximately $0.2 \times 0.2 \mathrm{~mm}^{2}$ elements), thus allowing to accurately capture stress variations [29]. The joints were simulated with two-dimensional FE models, using 4-node plane-strain elements (CPE4 from Abaqus ${ }^{\mathbf{s}}$ ) and COH2D4 4-node cohesive elements, compatible with the CPE4 elements [33]. Boundary conditions included clamping the joints at one of the edges, to reproduce the testing machine gripping, while the opposite edge was pulled in tension together with lateral restraining (Fig. 1). The adhesive layer was modelled with a single row of cohesive elements [27] and a damage model 
between each set of paired nodes with varying CZM shape, as defined in Section 3.2. This technique is implemented in Abaqus ${ }^{\mathbf{s}}$ $\mathrm{CAE}$ and will be briefly described for the different types of cohesive laws evaluated.

\subsection{CZM implementation in the FE analysis}

CZM reproduce the elastic loading up to a peak load, damage onset and crack growth due to local failure. CZM are typically founded on a relationship between stresses/cohesive tractions and relative displacements (in tension or shear) that connect
homologous nodes of the cohesive elements, to simulate the elastic behaviour up to $t_{\mathrm{n}}^{0}$ (tension) or $t_{\mathrm{s}}^{0}$ (shear) and subsequent stiffness reduction, related to the progressive material degradation up to final failure $[37,38]$. In this work the triangular, linearexponential and trapezoidal shapes were evaluated (Fig. 3 schematically represents these three CZM shapes with the associated nomenclature). As shown in Fig. 3, the linear-exponential law is linear up to $t_{\mathrm{n}}$ or $t_{\mathrm{s}}$, and afterwards undergoes an exponential softening up to failure. This shape is an approximation of the fullexponential law [20], providing in this case a more abrupt stress drop than the triangular law, after the peak loads are achieved. $G_{\mathrm{n}}$ and $G_{\mathrm{s}}$ are the areas under the CZM laws in tension or shear, respectively. The definition of the normal or shear maximum relative displacements $\left(\mathrm{d}_{\mathrm{n}}^{\mathrm{f}}\right.$ and $\mathrm{d}_{\mathrm{s}}^{\mathrm{f}}$, respectively) is carried out by making $G_{\mathrm{n}} 1 / 4 \stackrel{c}{G_{\mathrm{n}}}$ for tension or $G_{\mathrm{s}} 1 / 4 G_{\mathrm{s}}$ for shear. The initial linear elastic behaviour in the CZM laws (notwithstanding their shape) is defined by an elastic constitutive matrix relating the current stresses and strains in tension and shear across the interface (subscripts $\mathrm{n}$ and $\mathrm{s}$, respectively) [39]

$\mathbf{t}=\left\{\begin{array}{l}t_{\mathrm{n}} \\ t_{\mathrm{s}}\end{array}\right\}=\left[\begin{array}{ll}K_{\mathrm{nn}} & K_{\mathrm{ns}} \\ K_{\mathrm{ns}} & K_{\mathrm{ss}}\end{array}\right]\left\{\begin{array}{l}\varepsilon_{\mathrm{n}} \\ \varepsilon_{\mathrm{s}}\end{array}\right\}=\mathbf{K} \boldsymbol{\varepsilon}$.

$t_{\mathrm{n}}$ and $t_{\mathrm{s}}$ represent the cohesive tractions in tension and shear, respectively, whilst $e_{n}$ and $e_{s}$ are the tensile and shear strain, in the same order. The stiffness matrix, K, contains the adhesive stiffness parameters. A suitable approximation for thin adhesive layers is provided with $K_{\mathrm{nn}} 1 / 4 E, K_{\mathrm{ss}} 1 / 4 G, K_{\mathrm{ns}}{ }^{1 / 40}[21,40]$. For all of the three CZM shapes, initiation of damage was evaluated by the following quadratic nominal stress criterion, previously tested for accuracy [14], and expressed as [39]

$$
\left\{\frac{\left\langle t_{\mathrm{n}}\right\rangle}{t_{\mathrm{n}}^{0}}\right\}^{2}+\left\{\frac{t_{\mathrm{s}}}{t_{\mathrm{s}}^{0}}\right\}^{2}=1
$$

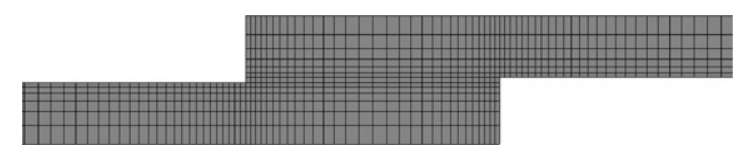

Fig. 2. Detail of the mesh for the $L_{0}^{1 / 4} 10 \mathrm{~mm}$ model.

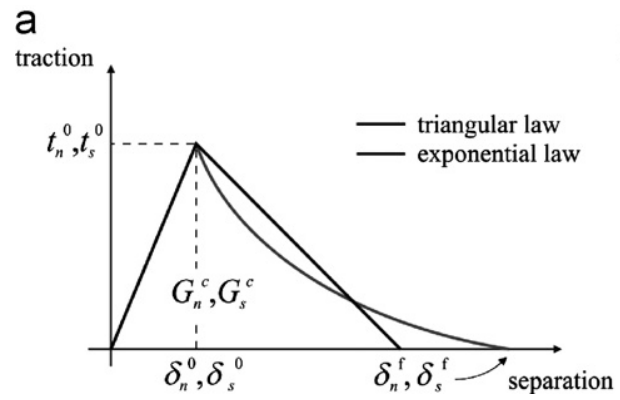

hi are the Macaulay brackets, emphasising that a purely compressive stress state does not initiate damage. Thus, initiation of damage is coupled between tension and shear [41]. After the criterion of Eq. (2) is met, the material stiffness initiates a degradation process. However, from this point on, an uncoupled tensile/shear behaviour was used, in which the tensile and shear behaviours of the CZM elements are independent up to failure. This choice was made because of the Abaqus ${ }^{\mathbf{s}}$ unavailability of mixed-mode coupling criteria for the trapezoidal CZM formulation.

The softening regions of the CZM laws are defined in Abaqus ${ }^{s}$ by specification of the damage variable $\left(d_{\mathrm{n}}\right.$ for tension or $d_{\mathrm{s}}$ for shear), as a function of $d_{n}-d_{A}$ (tension) or $d_{s_{-}} d_{s}$ (shear), i.e., as a function of the effective displacement beyond damage initiation $\left(\mathrm{d}_{\mathrm{n}}\right.$ and $\mathrm{d}_{\mathrm{s}}$ represent the damage onset relative displacements in tension and shear, respectively). This is described by the following formulae. Fig. 4 pictures the definition of $d_{\mathrm{n}}$ for the triangular law, although it can be extrapolated to $d_{\mathrm{s}}$ [39]

$$
\begin{aligned}
& t_{\mathrm{n}}=\left(1-d_{\mathrm{n}}\right) t_{\mathrm{n}}^{\text {und }} \\
& t_{\mathrm{s}}=\left(1-d_{\mathrm{s}}\right) t_{\mathrm{s}}^{\text {und }},
\end{aligned}
$$

where $t_{\mathrm{n}}^{\text {und }}$ and $t_{\mathrm{s}}^{\text {und }}$ are the current cohesive tractions in tension and shear, respectively, without stiffness degradation. In this expression, $d_{\mathrm{n}, \mathrm{s}} 1 / 40$ for an undamaged material (in the elastic region) and $d_{n, \mathrm{~s}} 1 / 41$ for a fully damaged material. By this principle, the generic expression (in tension or shear) of $d_{\mathrm{n}, \mathrm{s}}$ for the triangular law takes the form [39]

$$
d_{n, s}=\frac{\delta_{n, s}^{f}\left(\delta_{n, s}-\delta_{n, s}^{0}\right)}{\delta_{n, s}\left(\delta_{n, s}^{f}-\delta_{n, s}^{0}\right)}
$$

For the exponential law, the expression of $d_{\mathrm{n}, \mathrm{s}}$ gives [39]

$$
d_{n, s}=1-\frac{\delta_{n, s}^{0}}{\delta_{n, s}}\left(1-\frac{1-e^{\left(-\alpha\left(\delta_{n, s}-\delta_{n s}^{0} / \delta_{n, s}^{f}-\delta_{n s,}^{0}\right)\right)}}{1-e^{(-\alpha)}}\right),
$$

where $\mathrm{a}$ is a non-dimensional parameter, related to a specific material, that establishes the rate of damage evolution with $d_{n, s}$ (for $\mathrm{a}^{1 / 4} \mathrm{O}$ a triangular law is attained). In this work, $\mathrm{a}^{1 / 4} 7$ was chosen to provide a significant difference to the triangular shape, by a significantly faster degradation after $t_{\mathrm{n}}^{0}$ is reached. For the trapezoidal law, the stress softening displacements in tension and shear, $d_{n}^{s}$ and $d_{s}^{s}$, respectively, are introduced. The value of $d_{n, s}$ is divided into the constant stress region $\left(d_{n, s}^{0} O d r_{n, s}^{s} ;\right.$ Fig. 3) and softening region $\left(\mathrm{d}_{\mathrm{n}, \mathrm{s}} \mathbf{O} \mathrm{d} \mathbf{r} \mathrm{d}_{\mathrm{n}, \mathrm{s}} ;\right.$ Fig. 3$)$ as follows [39]:

$$
\mid \begin{array}{lll}
d_{n, s}=1-\frac{\delta_{n s}^{0}}{\delta_{n s}} & \text { if } & \delta_{n, s}^{0}<\delta \leq \delta_{n, s}^{s} \\
d_{n, s}=1-\frac{m \delta_{n, s}+b}{K_{n, s} \delta_{n, s}} & \text { if } & \delta_{n, s}^{s}<\delta \leq \delta_{n, s}^{f}
\end{array} .
$$

The values of $m$ and $b$ relate to the straight line equation of the decaying portion of the CZM law with respect to the $t$-d plot

b

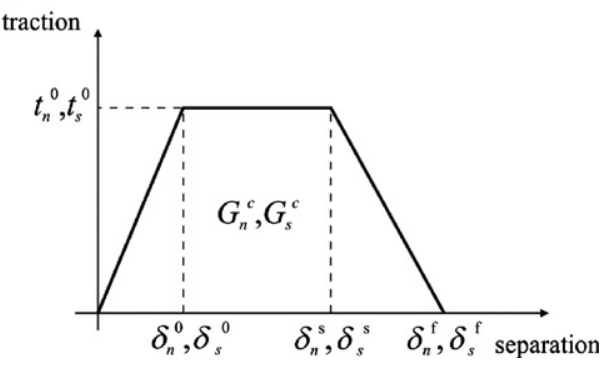

Fig. 3. CZM laws with triangular, exponential and trapezoidal shapes available in Abaqus ${ }^{\text {s }}$ 
origin, given by [39]

$$
m=\frac{-t_{n, s}^{0}}{\delta_{n, s}^{f}-\delta_{n, s}^{s}} \quad ; \quad b=t_{n, s}^{0}-m \delta_{n, s}^{s}
$$

The values of $d_{n, s}^{f}$ are found by consideration of the area under the $t-\mathrm{d}$ plot to be equal to $G_{\mathrm{n}, \mathrm{s}}^{\mathrm{O}} \mathrm{On}$ the other hand, several techniques are available for the definition of $\mathrm{d}_{\mathrm{s}}^{\mathrm{s}}$ (trapezoidal law), such as pre-established ratios between $\mathrm{d}_{\mathrm{n}, \mathrm{s}}$ and $\mathrm{d}_{\mathrm{n}, \mathrm{s}}$ [42], use of experimental failure strain data [21], or pre-established

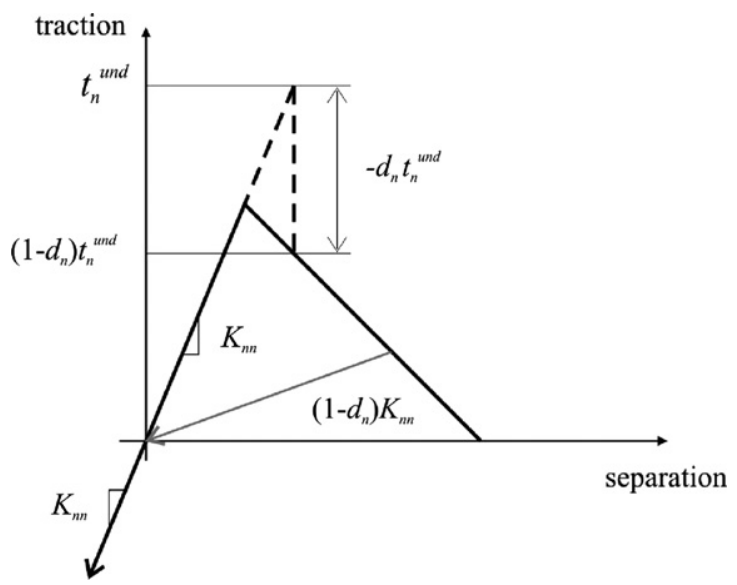

Fig. 4. Definition of the damage variable in tension, $d_{n}$, in Abaqus ${ }^{s}$ (extrapolation is possible for $d_{s}$ ).

Table 3

Cohesive parameters of the adhesives Araldite ${ }^{\mathbf{s}}$ AV138 and 2015 for CZM modelling.

\begin{tabular}{lll}
\hline Property & AV138 & 2015 \\
\hline$E[\mathrm{GPa}]$ & 4.89 & 1.85 \\
$G[\mathrm{GPa}]$ & 1.56 & 0.56 \\
$t_{\mathrm{n}}^{\mathrm{O}}[\mathrm{MPa}]$ & 39.45 & 21.63 \\
$t_{\mathrm{s}}^{\mathrm{o}}[\mathrm{MPa}]$ & 30.2 & 17.9 \\
$G_{\mathrm{n}}^{\mathrm{c}}[\mathrm{N} / \mathrm{mm}]$ & 0.20 & 0.43 \\
$G_{\mathrm{s}}^{\mathrm{c}}[\mathrm{N} / \mathrm{mm}]$ & 0.38 & 4.70 \\
\hline
\end{tabular}

a
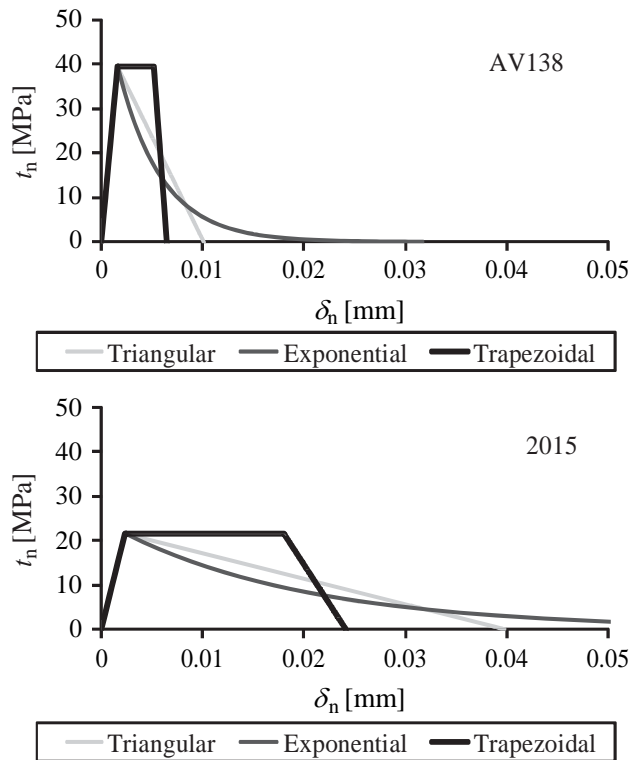

decaying slope up to $\mathrm{d}_{\mathrm{n}}^{\mathrm{f}}$ (e.g. identical slope between the tensile and shear CZM laws, if only tensile data is available) [43]. In this wark, the first approach was adopted considering $\mathrm{d}_{\mathrm{n}, \mathrm{s}} / \mathrm{d}_{\mathrm{mer}} \mathrm{s}^{1 / 4} \mathrm{C} / \mathrm{M}$

laws, estimated from the experimental data of Table 2 and considering the average values of the experiments. Fig. 5 details the CZM laws with different shapes for the adhesives 2015 and AV138 in tension (a) and shear (b).

\subsection{Feasibility of uncoupling the damage evolution}

As it was mentioned in the previous section, the CZM formulation adopted in this work is uncoupled in tension and shear after damage initiation. To assess the influence of this simplifying assumption and to guarantee the validity of the $\mathrm{FE}$ predictions throughout this work, a numerical analysis was performed by comparing, for the Araldite $\mathbf{s} 2015$ and the entire range of $L_{O}$ values considered in the analysis, the predicted values of maximum load $\left(P_{\mathrm{m}}\right)$ between the uncoupled and full mixedmode formulations. This comparison is performed considering the triangular law as an example, since it is readily available with a mixed-mode formulation. Moreover, only the Araldite $^{\mathbf{S}} 2015$

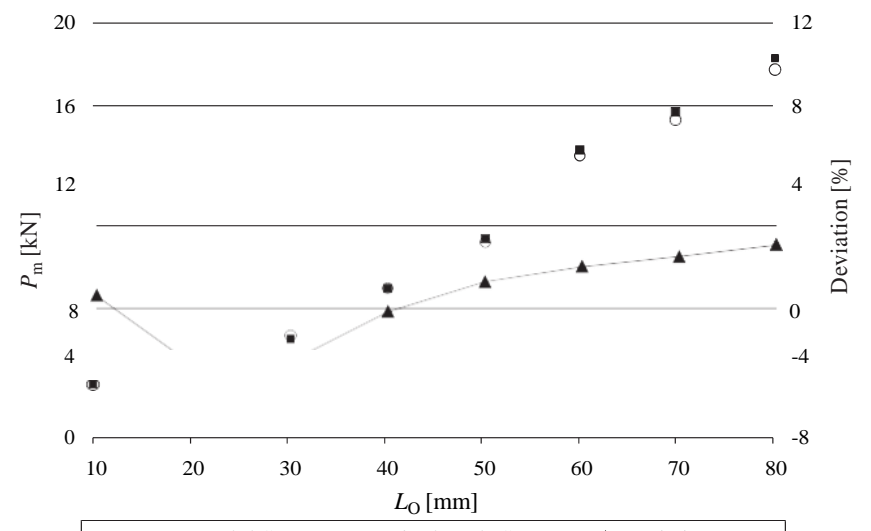

- Uncoupled CZM $\quad$ O Mixed-mode CZM $\quad$ ^-Deviation [\%]

Fig. 6. Numerical comparison between the uncoupled and full mixed-mode formulations for the Araldite ${ }^{\mathbf{S}} 2105$ and respective deviation.

b
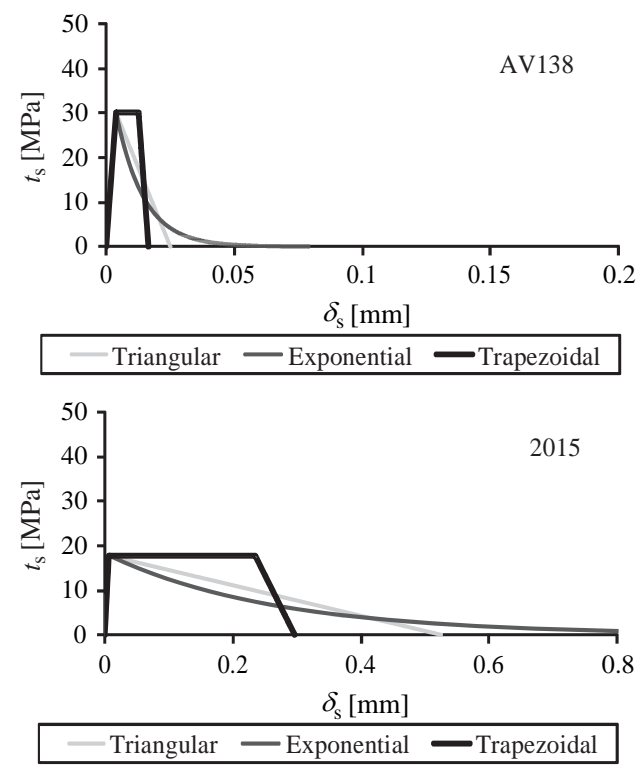

Fig. 5. CZM laws in tension (a) and shear (b) for both the adhesives tested. 


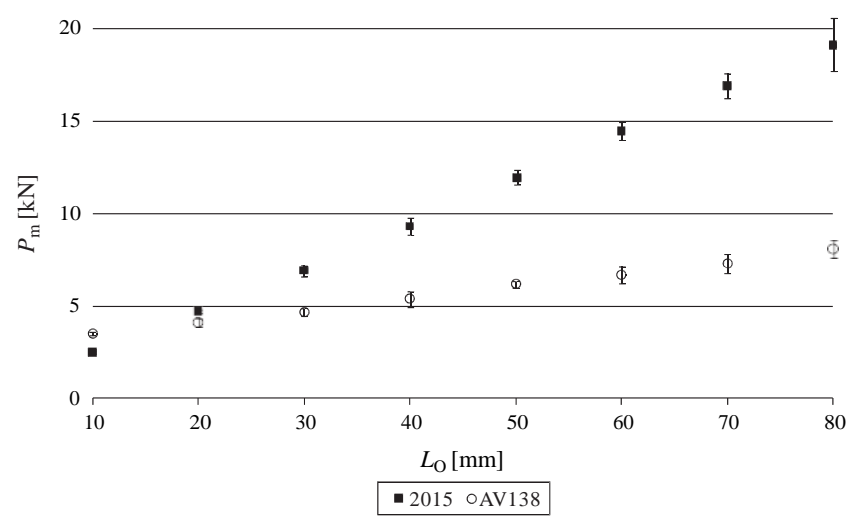

Fig. 7. Experimental plot of the $P_{\mathrm{m}}-L_{\mathrm{O}}$ values for the adhesives AV138 and 2015.

results are presented here since, owing to its ductility, it yields bigger differences than the Araldite ${ }^{\mathbf{s}}$ AV138, whose variation between the two approaches was negligible (fewer than $0.5 \%$ ). For the mixed-mode formulation, failure was predicted by a linear power law form of the required energies for failure in the pure modes [39]

$$
\frac{G_{\mathrm{n}}}{G_{\mathrm{n}}^{\mathrm{c}}}+\frac{G_{\mathrm{s}}}{G_{\mathrm{s}}^{c}}=1
$$

Fig. 6 shows the numerical comparison of $P_{\mathrm{m}}$ values between the uncoupled and full mixed-mode formulations for the Araldite $^{\mathbf{s}} 2105$ and respective deviation. The deviation plot shows that for small values of $L_{\mathrm{O}}$ the uncoupled formulation tends to slightly underestimate $P_{\mathrm{m}}$ (up to $2.76 \%$, for $L_{\mathrm{O}} 1 / 420 \mathrm{~mm}$ ). On the other, for bigger values of $L_{\mathrm{O}}$, the uncoupled response gradually overshoots by an increasing amount the $P_{\mathrm{m}}$ prediction, up to $3.10 \%$ for $L_{0} 1 / 480 \mathrm{~mm}$. On account of these results, the authors thus conclude that, for the range of $L_{O}$ values addressed in this work, the uncoupled formulation is a suitable approximation.

\section{Results and discussion}

\subsection{Joint strength}

All the joints experienced a cohesive failure of the adhesive layer. Previously to the analysis, a mesh dependency study was carried out to ascertain if the selected mesh refinement is enough to ensure convergence to the right solution. This analysis considered the joints with both adhesives and with $L_{0} 1 / 410$ and $80 \mathrm{~mm}$, which give the most significant difference in the adhesive layer stress state. Increasing refinements were considered, with element lengths at the overlap edges of $0.05,0.1,0.2$ and $0.4 \mathrm{~mm}$. Maximum deviations of $0.3 \%$ were found relatively to the average value of $P_{\mathrm{m}}$ between the four mesh sizes (independent analysis for each adhesive). This behaviour was expected, since in CZM modelling an energetic criterion is used for damage propagation, based on the input values of $G_{\mathrm{n}}^{\mathrm{c}}$ and $G_{\mathrm{s}}^{\mathrm{c}}$. Since the energy required for crack growth is averaged over the damaged area, results are mesh independent provided that a minimum refinement is used, more specifically if a minimum of three to four elements are undergoing the softening process at the damage front $[21,44]$.

Fig. 7 reports $P_{\mathrm{m}}$ as a function of $L_{\mathrm{O}}$ for both adhesives tested, showing a nearly linear increase of $P_{\mathrm{m}}$ with $L_{\mathrm{O}}$. The non-existence of a limiting $P_{\mathrm{m}}$ value in the $P_{\mathrm{m}}-L_{\mathrm{O}}$ curves is justified by the high strength of the CFRP (i.e., the tensile strength of the laminates was not attained for the tested $L_{O}$ values up to failure in the adhesive layer). Actually, the maximum value of longitudinal axial stresses
$\left(\mathbf{S}_{\mathrm{x}}\right)$ was found for the joints with $L_{\mathrm{O}} 1 / 480 \mathrm{~mm}$ (610.7 MPa for the joints with Araldites 2015 and $393.9 \mathrm{MPa}$ for the joints with Araldite $^{\mathbf{s}}$ AV138), being much smaller in magnitude to the tensile strength of the employed composite, of E $2000 \mathrm{MPa}$ [14]. Adding to this, a detailed stress analysis to the joints for the range of $L_{O}$ values used in this work was undertaken. It was possible to conclude that, owing to the adherends stiffness and respective lack of plastic flow, the average shear stress along the bondline for both adhesives tends to diminish at the time of joint failure, but this reduction is exponential, with smaller reductions for the bigger $L_{\mathrm{O}}$ values (e.g. for the AV 138 between $L_{\mathrm{O}} 1 / 470$ and $80 \mathrm{~mm}$, the reduction of the average shear stress was only $6.9 \%$ ). By the combined effect of this reduction and of the increase of $L_{0}$, an improvement of $P_{\mathrm{m}}$ was found for the entire range of $L_{O}$ values tested. However, for different overall conditions, e.g. adherends with a smaller value of $E$, a constant value of $P_{\mathrm{m}}$ could be attained in the $P_{\mathrm{m}}-L_{\mathrm{O}}$ plots at a relatively small value of $L_{\mathrm{O}}$ on account of a steeper reduction of the average shear stress along the bondline at failure with the increase of $L_{\mathrm{O}}$ [45]. Analysing Fig. 7 in more detail, for $L_{\mathrm{O}} 1 / 410 \mathrm{~mm}$ the AV138 shows a larger $P_{\mathrm{m}}$ value than the 2015 , which is accredited to the bigger adhesive strength (Table 3), and to the fact that shear stresses, which rule the failure process, are nearly constant over the overlap for very short overlaps [3]. As a result, failure depends almost exclusively on the adhesive strengths, whilst the fracture toughness (much bigger for the 2015) becomes irrelevant. For increasing values of $L_{0}$, the 2015 shows a steeper increase of $P_{\mathrm{m}}$ than the AV138, because it is extremely ductile (Table 2) and the joints fail with a significant degree of plastic flow in the adhesive layer [45]. In fact, adhesive plasticisation takes place at the overlap edges where stresses peak, together with redistribution of stresses in the adhesive layer towards the inner overlap regions [46,47]. Because of this issue, a nearly proportional relationship exists between $P_{\mathrm{m}}$ and $L_{\mathrm{O}}$ in Fig. 7. To further corroborate this fact, fracture was always abrupt in the test specimens, only with a negligible crack growth before $P_{\mathrm{m}}$ for the bigger values of $L_{\mathrm{O}}$. This shows that the adhesive plasticity always held up crack initiation at the overlap edges up to $P_{\mathrm{m}}$, keeping these regions at the peak strength, while stresses increased at the inner regions [48]. On the other hand, the AV138 shows a steady but significantly smaller improvement of $P_{\mathrm{m}}$ with $L_{O}$, due to its brittleness, testified by the corresponding values of $G_{n, s}^{c}$ (Table 2). Adding to this, $S_{y}$ peak stresses at the overlapends progressively increase in magnitude with $L_{\mathrm{O}}$ [3], as they gradually concentrate in a smaller region because of more localised bending of the adherends at the overlap edges. This, added to the reduced allowance of adhesive plastic flow (small value of $G_{\mathrm{n}}^{\mathrm{c}}$ ), gives a lesser advantage in the single-lap joints strength with the increase of $L_{\mathrm{O}}$.

\subsection{Cohesive law shape effects}

The CZM law shape influence on the strength predictions was carried out considering triangular, exponential and trapezoidal $\mathrm{CZM}$, for a perception of the influence of this choice on the accuracy of the FE simulations under different material/geometrical conditions. Initial emphasis is given to the size of the predicted length of the process zone at $P_{\mathrm{m}}$ (immediately before fracture), for a better understanding of the failure processes and differences between the FE models with distinct CZM shapes for the adhesive layer. To this end, the shear process zone was considered, as it is the most significant to the failure process, and it was measured for the joints with $L_{0} 1 / 410$ and $80 \mathrm{~mm}$, which represent the limiting scenarios of $L_{\mathrm{O}}$. Only the results for the Araldite $^{s} 2015$ are presented, because any difference between models is more easily detected on account of the adhesive ductility, although the conclusions are identical to the Araldites 


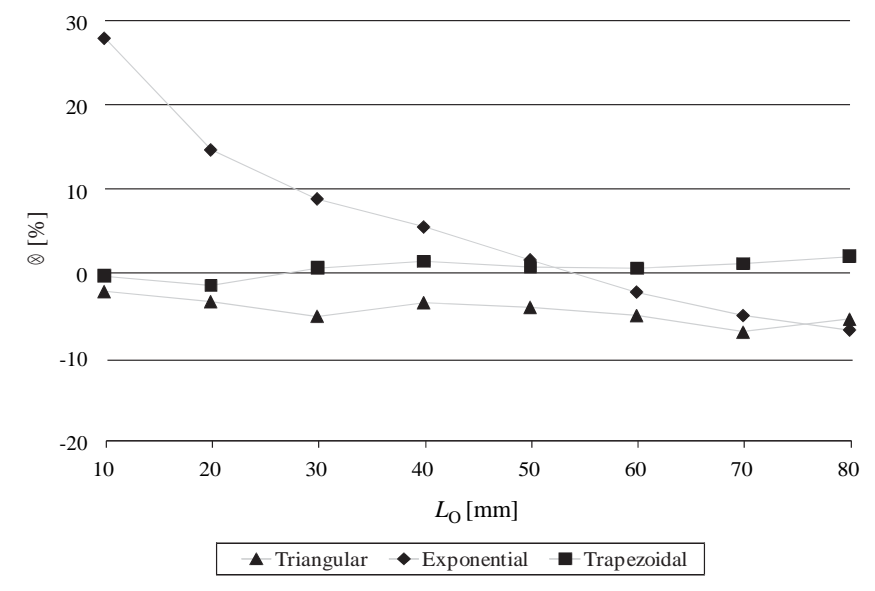

Fig. 8. Percentile deviation between the experimental and FE $P_{\mathrm{m}}$ values for the adhesive 2015

AV138. For $L_{\mathrm{O}} 1 / 410 \mathrm{~mm}$, the process zone extents at $P_{\mathrm{m}}$ were as follows (averaged over $L_{0}$ ): trapezoidal law $-79.1 \%$, triangular law-88.8\% and exponential law-100\%. For $L_{\mathrm{O}} 1 / 480 \mathrm{~mm}$, the following data was obtained: trapezoidal law-90.2\%, triangular law-94.5\% and exponential law-100\%. These results are in agreement with the plotted laws used to model the adhesive (Fig. 5), showing that the extent of damage is largest for the exponential law, followed by the triangular and trapezoidal laws, by the respective order. However, as it will be discussed further in this Section, this does not necessarily implies bigger values of predicted $P_{\mathrm{m}}$ by the exponential law, as the triangular and more specifically the trapezoidal laws allow bigger transmission of loads at the initial stages of damage (Fig. 5).

\subsubsection{Single-lap joints with the ductile adhesive}

Fig. 8 reports the percentile deviation (D) between the experi-

mental and FE $P_{\mathrm{m}}$ values for the adhesive 2015 (averaged by the respective experimental $P_{\mathrm{m}}$ values). The slight inconsistent trend of the $P_{\mathrm{m}}-L_{\mathrm{o}}$ plots is related to the calculation process to average experimental data, giving natural oscillations. Results show that the trapezoidal law approximates the best the experimental data. The percentile errors between the experimental and FE data are negligible, with a maximum of $1.9 \%$ for $L_{\mathrm{O}} 1 / 480$. These results are consistent with previous observations for these types of adhesives

$[21,24]$. Thus, the large plastic flow of the adhesive at a constant level of stresses after attaining the peak strength is captured by the FE simulations, by using damage definitions that correspond to a constant level of stresses at the end of the elastic region. The use of a triangular law showed to consistently underestimate $P_{\mathrm{m}}$, with a clear tendency for bigger discrepancies with larger values of $L_{\mathrm{O}}\left(\mathrm{D}^{1 / 4}-2.2 \%\right.$ for $L_{\mathrm{O}} 1 / 410 \mathrm{~mm}$, growing steadily for bigger $L_{\mathrm{O}}$ values; $\mathrm{D}^{1 / 4}-5.5 \%$ for $L_{\mathrm{O}} 1 / 480 \mathrm{~mm}$ ). The described tendency is justified in light of the typical stress distributions (namely shear stresses) for single-lap joints. As a fact, for small values of $L_{0}$, the nearly constant level of shear stresses between overlap ends [3] makes the CZM law shape practically irrelevant because at the time $P_{\mathrm{m}}$ is attained, the adhesive is evenly loaded in all its length. In the FE analyses, this corresponds to a scenario in which the stress levels are close to $t^{0}$ along the entire bond, which renders the softening shape of the CZM law not so important. With bigger values of $L_{\mathrm{O}}$ the stress gradients increase [3] and the deviation to the experimental data enlarges as well. Despite the variations to the experimental results, the triangular law still manages to predict $P_{\mathrm{m}}$ with an acceptable accuracy, which is an important feature to mention, as it is the easiest CZM law to use in terms of implementation, time of calculation, CZM parameter definition and availability in commercial FE codes. The use of more compliant adherends would reduce this deviation even further because of bigger stress gradients along the overlap [23]. On the other hand, adherends such as steel would increase this deviation. The exponential CZM gave opposite results for the range of $L_{0}$ values evaluated. For small values of $L_{\mathrm{O}}, P_{\mathrm{m}}$ was numerically overestimated (maximum D of $27.9 \%$ for $L_{O} 1 / 410 \mathrm{~mm}$ ). The $\mathrm{D}$ values consistently reduced and approached the experimental results for $L_{\mathrm{O}} 1 / 450 \mathrm{~mm}$. From this point, under predictions of $P_{\mathrm{m}}$ were obtained with exponential softening (reaching D1/4- 6.8\% for $L_{\mathrm{O}} 1 / 480 \mathrm{~mm}$ ). Analysis of the $\mathrm{FE}$ results showed that the over estimation of $P_{\mathrm{m}}$ for the smaller $L_{\mathrm{O}}$ values is due to the following motives:

(1) With the reduction of $L_{O}$, peel peak stresses develop at a larger normalised region of $L_{O}[3]$. With the increase of $L_{O}$, peel peak stresses concentrate at smaller normalised regions of $L_{\mathrm{O}}$. This difference makes the preponderance of peel stresses not negligible for small $L_{\mathrm{O}}$ values. The over estimation of $P_{\mathrm{m}}$ for small $L_{\mathrm{O}}$ values is thus linked to the bigger value of $\mathrm{d}_{\mathrm{n}}^{\mathrm{f}}$ for the exponential law (Fig. 5a), which leads to failure at the overlap edges at higher values of $P_{\mathrm{m}}$. The peel stresses extension (normalised over the overlap) rapidly diminishes with the increase of $L_{\mathrm{O}}$, reducing the error of the CZM predictions with the exponential law.

(2) With the reduction of $L_{O}$, owing to the bigger value of $\mathrm{d}^{\mathrm{f}}$ for the exponential law induced by the steeper reduction of $t_{\mathrm{s}}$ after $t_{\mathrm{s}}$ is attained, and also to a state of approximately constant shear stresses [3], the CZM elements of the inner overlap region at the time of failure show smaller degradation (i.e., higher transmitted loads), and thus the predicted $P_{\mathrm{m}}$ values artificiallyincrease.

Figs. 9 and 10 show the $P$-d curves for the joints with $L_{\mathrm{O}} 1 / 410$ and $80 \mathrm{~mm}$, respectively, bonded with the Araldite ${ }^{\mathrm{s}} 2015$. The experimental and $\mathrm{FE}$ curves are in reasonable agreement, in which regards to the joint stiffness and values of $P_{\mathrm{m}}$ (this issue is discussed in detail further in this work). On the other hand, the experimental failure displacements are slightly bigger than the $\mathrm{FE}$ ones, owing to minor slippage of the specimens in the machine grips. It is also observed that the FE stiffness between CZM shapes is identical up to $P_{\mathrm{m}}$, whilst the predictions mainly differ in the value of $P_{\mathrm{m}}$. These figures were chosen because they represent the minimum and maximum values of $L_{0}$ for the Araldite ${ }^{\mathbf{S}} 2015$, allowing the analysis of the predicted behaviour for the limit

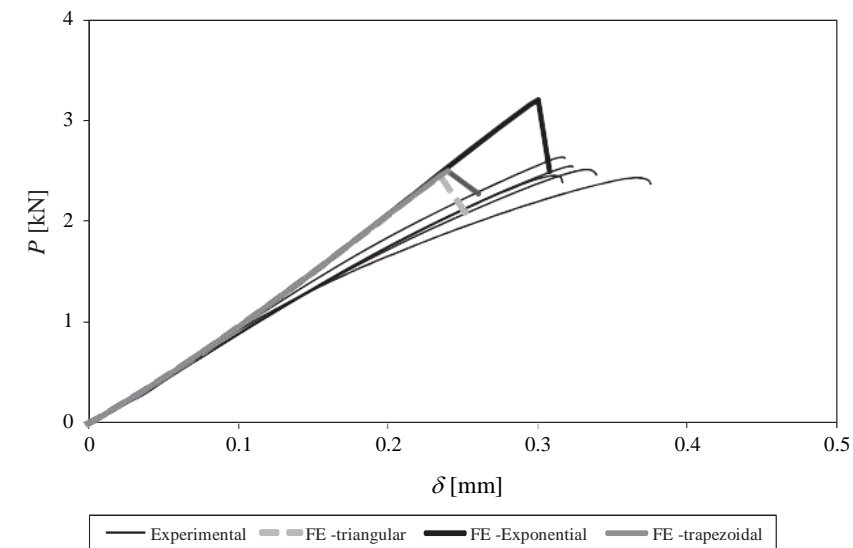

Fig. 9. Experimental and numerical $P-\mathrm{d}$ curves for the joints with $L_{0} 1 / 410 \mathrm{~mm}$ bonded with the Araldites 2015 
values of $L_{\mathrm{O}}$, and clearly showing the differences in $P_{\mathrm{m}}$ reported in Fig. 8. The correlations obtained for these two conditions are also valid for the other values of $L_{0}$ and for the Araldites AV138, although the curves are not presented here.

\subsubsection{Single-lap joints with the brittle adhesive}

Fig. 11 provides an identical comparison for the adhesive $\mathrm{AV} 138$, in which the oscillations are due to the aforementioned experimental variations. A large discrepancy can be readily observed in which regards the order of magnitude of $\mathrm{D}$, since for the AV138 the maximum deviation is near 3\%, compared to the approximate $30 \%$ for the 2015 . On the other hand, the results of all the three CZM configurations follow the same tendency for

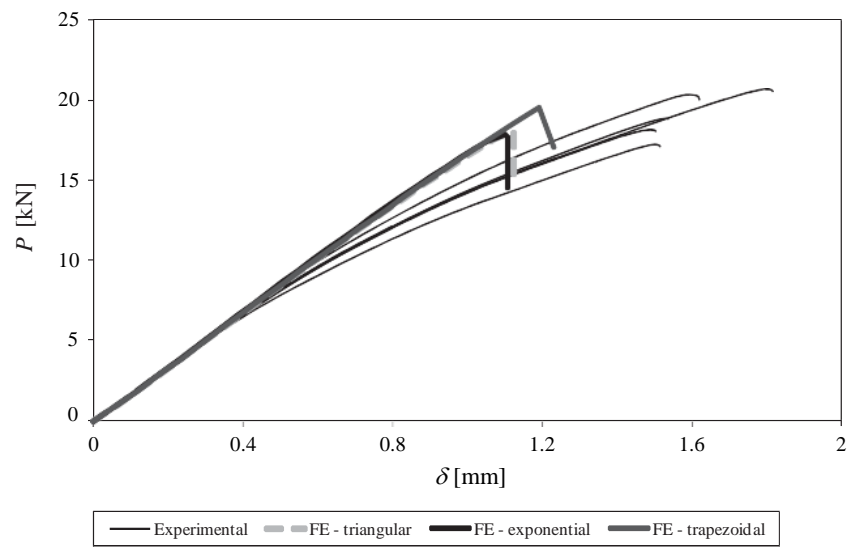

Fig. 10. Experimental and numerical $P$-d curves for the joints with $L_{\mathrm{O}} 1 / 480 \mathrm{~mm}$ bonded with the Araldite ${ }^{\mathbf{S}} 2015$.

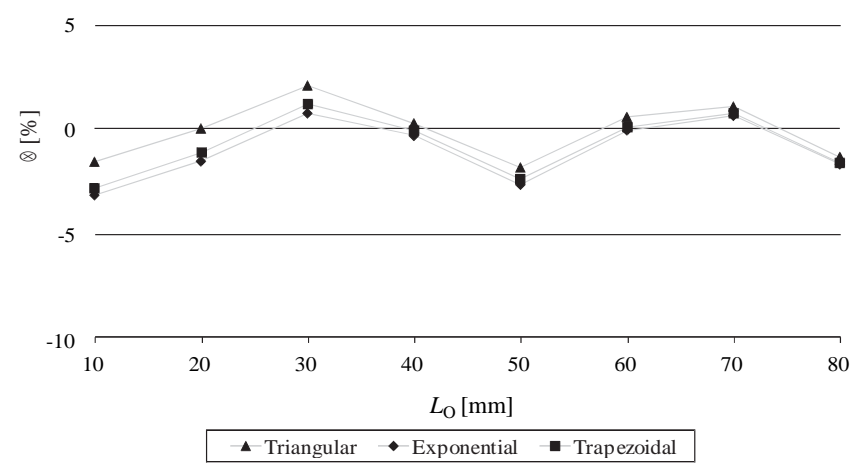

Fig. 11. Percentile deviation between the experimental and FE $P_{\mathrm{m}}$ values for the adhesive AV138. the entire range of $L_{\mathrm{O}}$ values. This is related to the brittleness of the AV138, especially when compared to the large ductility of the 2015, which can be testified in Fig. 5 by disparity in the $d_{n, s}$ values. Actually, for the shear behaviour (Fig. $5 b$ ), $d_{s}$ for the 2015 is more than one order of magnitude higher than for the AV138. As a result of this difference, the CZM shape of the AV138 is much less influent because the region under softening is negligible when compared to that of the 2015. This can be observed in Fig. 12, which compares joints with $L_{O} 1 / 480 \mathrm{~mm}$ bonded with the 2015 (a) and AV138 (b) when $P_{\mathrm{m}}$ is attained (trapezoidal CZM). The parameter SDEG corresponds to $d_{s}$, i.e. the stiffness degradation in shear, with SDEG $1 / 40$ relating to the undamaged material and SDEG $1 / 41$ to complete failure. Since the region of influence of the CZM laws for the AV138 is restricted to a small portion of the overlap, any differences in shape have a reduced effect. The same tendency between all three CZM shapes is also a result of this, although a slight reduction of $\mathrm{D}$ between the three shapes occurs with the increase of $L_{0}$, with negligible variations for the bigger values of $L_{0}$. This variation can be accredited to the increasing degree of stress gradients in the adhesive bond, both peel and shear [3], which further reduces the bond length under softening, where the differences between the three CZM shapes appear. Under brittle conditions, all the CZM shapes revealed to be accurate in predicting the measured response of the joints, although the best results (especially for small values of $L_{\mathrm{O}}$ ) were found with the triangular law (maximum

value of $\mathrm{D}$ of $-1.9 \%$ for $L_{\mathrm{O}} 1 / 410 \mathrm{~mm}$ ). Compared to these and the experiments, the trapezoidal results showed a slight under prediction (maximum $\mathrm{D}^{1 / 4}-2.9 \%$ for $L_{\mathrm{O}} 1 / 410 \mathrm{~mm}$ ). The exponential CZM further under predicts $P_{\mathrm{m}}$ (maximum $\mathrm{D}^{1 / 4-3}$. $2 \%$ for $L_{\mathrm{O}} 1 / 410 \mathrm{~mm}$ ), although following the very same trend of the previously reported data.

\section{Concluding remarks}

The main purpose of this work was to evaluate the influence of the CZM shape used to model a thin adhesive layer in single-lap joints on the strength predictions, for different geometry/adhesive combinations. With this purpose, single-lap joints were bonded with a brittle and ductile adhesive and tested under tension, considering a large range of $L_{O}$ values, which allowed to test different bond solutions in which regards to stress distributions (short overlaps are usually related to small shear stress gradients, while large overlaps give rise to large stress concentrations). The experimental results initially showed a markedly different trend for both adhesives as a function of $L_{O}$, since the brittle adhesive resulted in a smaller improvement of $P_{\mathrm{m}}$ with $L_{\mathrm{O}}$, as the joints failed soon after the attainment of the adhesive strengths at the overlap ends. Oppositely, the joints bonded with the ductile adhesive showed a major strength improvement with

b
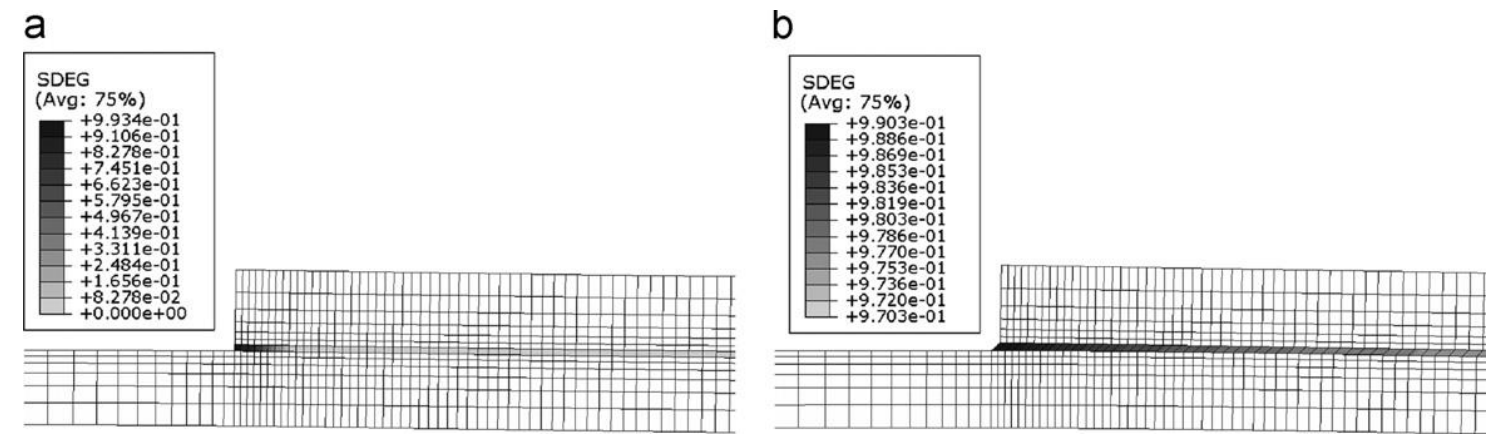

Fig. 12. Stiffness degradation for the joints with $L_{\mathrm{O}} 1 / 480 \mathrm{~mm}$ bonded with the 2015 (a) and AV138 (b) when $P_{\mathrm{m}}$ is attained (trapezoidal CZM). 
$L_{\mathrm{O}}$ on account of failure ruled by allowance of large plastic flow in the adhesive layer. Regarding the different CZM shapes, these showed a significant influence on the results for the joints bonded with the adhesive 2015 . These were more precisely modelled by the trapezoidal CZM that captured the adhesive plastic flow at the end of the elastic region, whilst the triangular CZM under predicted $P_{\mathrm{m}}$ up to $\mathrm{D}^{1 / 4}-5.5 \%$ for $L_{\mathrm{O}} 1 / 480 \mathrm{~mm}$. The exponential CZM showed over predictions of $P_{\mathrm{m}}$ for short overlaps (up to $27.9 \%$ ) and under predictions for long overlaps (up to $-6.8 \%$ ). For the AV138, the triangular CZM showed to be the most suited, although the results were very close between all CZM shapes tested (maximum deviations of $-1.9 \%,-2.9 \%$ and $-3.2 \%$ for the triangular, trapezoidal and exponential CZM, respectively). As a result of this study, some conclusions were established to properly select the CZM shape for a given adhesive, depending on its characteristics, but the importance of using the most suited CZM shape will invariably depend on the required precision and on CZM availability/easiness to use. Actually, triangular CZM are more widespread in commercial software, they are more straightforward to formulate, and give results faster on account of easier convergence. Overall, it was found that the influence of the CZM shape can be neglected when using brittle adhesives without compromising too much the accuracy, whilst for ductile adhesives this does not occur. Additionally, the smaller the value of $L_{0}$ and the adhesive ductility, the greater is the influence of the CZM shape. In the end, any use of a CZM shape not suited to the material/interface to be simulated has to be balanced in these issues and expected variations in accuracy.

\section{References}

[1] Lee MJ, Cho TM, Kim WS, Lee BC, Lee JJ. Determination of cohesive parameter for a mixed-mode cohesive zone model. Int. J. Adhes. Adhes. 2010;30:322-8.

[2] Banea MD, da Silva LFM. Adhesively bonded joints in composite materials: an overview. J. Mater.: Des. Appl. 2009;223:1-18.

[3] Campilho RDSG, Banea MD, Neto JABP, da Silva LFM. Modelling of single-lap joints using cohesive zone models: effect of the cohesive parameters on the output of the simulations. J. Adhes. 2012;88:513-33.

[4] Lai YH, Rakestraw MD, Dillard DA. The cracked lap shear specimen revisited - a closed form solution. Int. J. Solids Struct. 1996;33:1725-43.

[5] Wooley GR, Carver DR. Stress concentration factors for bonded lap joint. J. Aircr. $1971 ; 8: 817-20$.

[6] Tsai MY, Morton J. An evaluation of analytical and numerical solutions to the single-lap joint. Int. J. Solids Struct. 1994;31:2537-63.

[7] da Silva LFM, Campilho RDSG. Advances in Numerical Modelling of Adhesive Joints. Heidelberg: Springer; 2011.

[8] Feraren P, Jensen HM. Cohesive zone modelling of interface fracture near flaws in adhesive joints. Eng. Fract. Mech. 2004;71:2125-42.

[9] Li S, Thouless MD, Waas AM, Schroeder JA, Zavattieri PD. Use of a cohesivezone model to analyze the fracture of a fiber reinforced polymer-matrix composite. Compos. Sci. Technol. 2005;65:537-49.

[10] Blackman BRK, Brunner AJ, Williams JG. Mode II fracture testing of composites: a new look at an old problem. Eng. Fract. Mech. 2006;73:2443-55.

[11] Biel A, Stigh U. Effects of constitutive parameters on the accuracy of measured fracture energy using the DCB-specimen. Eng. Fract. Mech. 2008;75:2968-83

[12] Banea MD, da Silva LFM, Campilho RDSG. Temperature dependence of the fracture toughness of adhesively bonded joints. J. Adhes. Sci. Technol. 2010;24:2011-26.

[13] Campilho RDSG, Banea MD, Chaves FJP, da Silva LFM. eXtended Finite Element Method for fracture characterization of adhesive joints in pure mode I. Comput. Mater. Sci. 2011;50:1543-9.

[14] Campilho RDSG, de Moura MFSF, Pinto AMG, Morais JJL, Domingues JJMS. Modelling the tensile fracture behaviour of CFRP scarf repairs. Compos. BEng. 2009;40:149-57.

[15] Pandya KC, Williams JG. Measurement of cohesive zone parameters in tough polyethylene. Polym. Eng. Sci. 2000;40:1765-76.

[16] Carlberger T, Stigh U. Influence of layer thickness on cohesive properties of an epoxy-based adhesive - an experimental study. J. Adhes. 2010;86:814-33.

[17] Alfano G, Crisfield MA. Finite element interface models for the delamination analysis of laminated composites: mechanical and computational issues. Int. J. Numer. Methods Eng. 2001;50:1701-36.
[18] Allix O, Corigliano A. Modeling and simulation of crack propagation in mixedmodes interlaminar fracture specimens. Int. J. Fract. 1996;77:111-40.

[19] Chen J. Predicting progressive delamination of stiffened fibre-composite panel and by decohesion models. J. Thermoplast. Compos. Mater. 2002;15: 429-41.

[20] Chandra N, Li H, Shet C, Ghonem H. Some issues in the application of cohesive zone models for metal-ceramic interfaces. Int. J. Solids Struct. 2002;39: 2827-55.

[21] Campilho RDSG, de Moura MFSF, Domingues JJMS. Using a cohesive damage model to predict the tensile behaviour of CFRP single-strap repairs. Int. J. Solids Struct. 2008;45:1497-512.

[22] Liljedahl CDM, Crocombe AD, Wahab MA, Ashcroft IA. Damage modelling of adhesively bonded joints. Int. J. Fract. 2006;141:147-61.

[23] Pinto AMG, Magalha es AG, Campilho RDSG, de Moura MFSF, Baptista APM Single-lap joints of similar and dissimilar adherends bonded with an acrylic adhesive. J. Adhes. 2009;85:351-76.

[24] Ridha M, Tan VBC, Tay TE. Traction-separation laws for progressive failure of a bonded scarf repair of composite panel. Compos. Struct. 2010;93:1239-45.

[25] Campilho RDSG, de Moura MFSF, Ramantani DA, Morais JJL, Barreto AMJP, Domingues JJMS. Adhesively-bonded repair proposal for wood members damaged by horizontal shear using carbon-epoxy patches. J. Adhes. 2010;86: 649-70.

[26] Alfano G. On the influence of the shape of the interface law on the application of cohesive-zone models. Compos. Sci. Technol. 2006;66:723-30.

[27] Campilho RDSG, Banea MD, Pinto AMG, da Silva LFM, de Jesus AMP. Strength prediction of single- and double-lap joints by standard and extended finite element modelling. Int. J. Adhes. Adhes. 2011;31:363-72.

[28] Xie D, Salvi AG, Sun C, Waas AM, Caliskan A. Discrete cohesive zone model to simulate static fracture in 2D triaxially braided carbon fiber composites. J. Compos. Mater. 2006;40:2025-46.

[29] Campilho RDSG, de Moura MFSF, Domingues JJMS. Modelling single and double-lap repairs on composite materials. Compos. Sci. Technol. 2005;65 1948-58.

[30] Ji G, Ouyang Z, Li G, Ibekwe S, Pang SS. Effects of adhesive thickness on globa and local Mode-I interfacial fracture of bonded joints. Int. J. Solids Struct. 2010;47:2445-58

[31] Campilho RDSG, Pinto AMG, Silva RF, Banea MD, da Silva LFM. Strength improvement of adhesively-bonded joints using a reverse-bent geometry. J. Adhes. Sci. Technol. 2011;25:2351-68.

[32] da Silva LFM, da Silva RAM, Chousal JAG, Pinto AMG. Alternative methods to measure the adhesive shear displacement in the thick adherend shear test. J. Adhes. Sci. Technol. 2008;22:15-29.

[33] Campilho RDSG, de Moura MFSF, Ramantani DA, Morais JJL, Domingues JJMS. Buckling behaviour of carbon-epoxy adhesively-bonded scarf repairs. J. Adhes. Sci. Technol. 2009;23:1493-513.

[34] Neto JABP, Campilho RDSG, da Silva LFM. Parametric study of adhesive joints with composites. Int. J. Adhes. Adhes. 2012;37:96-101.

[35] Campilho RDSG, de Moura MFSF, Domingues JJMS. Computational modelling of the residual strength of repaired composite laminates using a cohesive damage model. J. Adhes. Sci. Technol. 2008;22:1565-91.

[36] Panigrahi SK, Pradhan BJ. Three dimensional failure analysis and damage propagation behaviour of adhesively bonded single lap joints in laminated FRP composites. Reinf. Plast. Compos. 2007;26:183-201.

[37] Turon A, Dá vila CG, Camanho PP, Costa J. An engineering solution for mesh size effects in the simulation of delamination using cohesive zone models. Eng. Fract. Mech. 2007;74:1665-82.

[38] Campilho RDSG, de Moura MFSF, Barreto AMJP, Morais JJL, Domingues JJMS. Fracture behaviour of damaged wood beams repaired with an adhesivelybonded composite patch. Compos. A-Appl. Sci. 2009;40:852-9.

[39] Abaqus ${ }^{5}$ HTML Documentation, Dassault Systemes, (2009).

[40] Campilho RDSG, de Moura MFSF, Ramantani DA, Morais JJL, Domingues JJMS Buckling strength of adhesively-bonded single and double-strap repairs on carbon-epoxy structures. Compos. Sci. Technol. 2010;70:371-9.

[41] Li S, Thouless MD, Waas AM, Schroeder JA, Zavattieri PD. Mixed-mode cohesive-zone models for fracture of an adhesively bonded polymer-matrix composite. Eng. Fract. Mech. 2006;73:64-78.

[42] Yang QD, Thouless MD, Ward SM. Numerical simulations of adhesivelybonded beams failing with extensive plastic deformation. J. Mech. Phys. Solids 1999; $47: 1337-53$

[43] Carlberger T, Stigh U. An explicit FE-model of impact fracture in an adhesive joint. Eng. Fract. Mech. 2007;74:2247-62.

[44] Kafkalidis MS, Thouless MD. The effects of geometry and material properties on the fracture of single lap-shear joints. Int. J. Solids Struct. 2002;39: 4367-83.

[45] Adams RD, Comyn J, Wake WC. Structural Adhesive Joints in Engineering. 2nd ed. London: Chapman \& Hall; 1997.

[46] McGeorge D. Inelastic fracture of adhesively bonded overlap joints. Eng. Fract. Mech. 2010;77:1-21.

[47] Davis M, Bond D. Principles and practices of adhesive bonded structural joints and repairs. Int. J. Adhes. Adhes. 1999;19:91-105.

[48] Hu FZ, Soutis C. Strength prediction of patch repaired CFRP laminates loaded in compression. Compos. Sci. Technol. 2000;60:1103-14. 